\title{
Effects of treatment of male and female rats in infancy with mifepristone on reproductive function in adulthood
}

\author{
P. van der Schoot and R. Baumgarten \\ Department of Endocrinology, Growth and Reproduction, Faculty of Medicine and Health Sciences, \\ Erasmus University Rotterdam, P.O. Box 1738, 3000 DR Rotterdam, The Netherlands
}

\begin{abstract}
Summary. Treatment of neonatal male and female rats with mifepristone $(1 \mathrm{mg}$ s.c. every 2 days from Day 1 to 15 or Day 4 to 18 of life) interfered with the normal development of their reproductive capacities and of the adrenal glands. The effect on the adrenal glands seemed only temporary. Effects on reproductive functions seemed permanent.

Female rats developed abnormalities in structure of the oviduct and ovarian capsule reminiscent of effects reported after perinatal treatment with androgen or oestrogen. During adulthood, anovulatory polyfollicular ovaries developed, reminiscent of rats treated with a small dose of androgen in infancy.

Males showed retardation of testicular growth and delay of puberty. During adulthood testes did not grow beyond $65 \%$ that of normal rats. Sexual behaviour was deficient in that ejaculations occurred only rarely; when ejaculations did occur, fertility was unimpaired. Males treated with mifepristone in infancy exhibited female sexual behaviour as adults after castration and injections of testosterone and oestradiol. All effects pointed to an insufficient action of testicular hormones in infancy to bring about normal 'masculinization'.

Mifepristone therefore appears to show 'teratogenic' actions in rats which affect female reproductive tract development and, in males and females, development of the systems underlying normal reproductive activity and functions in adulthood.
\end{abstract}

Keywords: mifepristone; antiprogestagen; reproductive development; teratogenesis

\section{Introduction}

Anti-progestagens are a class of compounds which hold promise for birth control and treatment of steroid-sensitive tumours (Bakker et al., 1987, 1989). In recent experiments (unpublished) we have studied effects on growth and development of the treatment of male and female rats as neonates with the progesterone-antagonist, mifepristone. In these studies body growth appeared unaffected. However, a marked reduction of testicular growth was noticed at the end of the treatment period in infancy. The reduction of testicular growth resulted in marked reduction of testicular weight in adulthood. These findings were the basis of further experiments to investigate adult reproductive function in male and female animals after treatment with mifepristone in infancy.

Mifepristone has become known as a potent anti-progestagenic drug. The compound also shows anti-glucocorticoid actions (Philibert et al., 1985). Our earlier in-vivo studies with adult female rats did not reveal any specific support of the latter action. In contrast, anti-progestagenic activity was markedly present throughout as indicated by uninterrupted vaginal smear cornification in rats with high blood concentrations of progesterone of luteal origin (van der Schoot et al., $1987,1989)$. In adult rats the compound has no inhibitory but rather a stimulatory action on the secretion of pituitary gonadotrophins (Bakker et al., 1987); this action might represent a direct 
effect of the compound on the pituitary gland but also an effect secondary to altered secretion of ovarian hormones (van der Schoot et al., 1990).

In the above analysis of the effect of mifepristone in infancy the compound was administered every other day from Day 4 of life. In view of the importance of the period immediately after birth for both male and female reproductive development (e.g. Grady et al., 1965; Gerall et al., 1967; Beach et al., 1969) it seemed of interest to examine possible teratogenic effects of mifepristone further by starting treatment on the day of birth.

\section{Materials and Methods}

\section{Animals}

The experiments were carried out with 2-3-month-old rats obtained from the Wistar breeding colony of TNORijswijk (Rijswijk, The Netherlands). The animals were housed in $14 \mathrm{~h}$ light and $10 \mathrm{~h}$ darkness (lights on 05:0019:00 h) and fed ad libitum a commercial diet (Standard Laboratory Diet: Hope Farms, Woerden, The Netherlands) and tap water. Females were impregnated by males of proven fertility. Animals were included in the experiments when the litter size was 9 or more. On Day 2 of lactation (Day 1 = day of parturition) litters were adjusted to 10 taking care that a 1:1 sex ratio was approached as much as possible.

Newborn male and female rats received every other day a s.c. injection of $1 \mathrm{mg}$ mifepristone (Roussel-Uclaf, Romainville, France) in $0.05 \mathrm{ml}$ of an oily suspension or olive oil only. In one experiment the treatment started on Day 4 and continued until Day 18. In another experiment the treatment started on the day of birth $(=$ Day 1$)$ and continued through Day 15 of life.

\section{Experiments}

Bodyweight development, adrenal glands and onset of puberty in males and females. Adrenal glands were excised at autopsy and the weight of the left organ was recorded. No effort was made to study adrenal glands histologically.

Puberty in female rats was examined by daily examination of the vaginal orifice from around Day 25 . Upon vaginal opening, daily vaginal smears were taken for 3-4 weeks to investigate ovarian activity. Puberty in male rats was examined by daily examination of the penis for cleavage of the balano-preputial skinfold. This event follows the pubertal onset of testicular testosterone secretion after an interval of particular duration (de Jong \& van der Schoot, 1979; van den Dungen et al., 1989a, b). 'Male puberty', defined as the time of the onset of increased testicular testosterone production, can thus be recorded non-invasively and with an ease similar to that of recording puberty in females with vaginal opening.

For all rats bodyweight was recorded weekly and, additionaliy, daily around the day of puberty as defined above.

Reproductive function in females. After vaginal smears had revealed the occurrence of regular vaginal smear cycles, females from both groups were put together with males of proven fertility at the age of 60 days. After 2.5 weeks, pregnant animals were caged singly and pregnancy outcome was recorded.

Another group of females was kept without males until Day 100. Then daily vaginal smears were taken for 2 weeks. After vaginal smears had revealed uninterrupted vaginal cornification in most of the rats, rats were caged overnight with males of proven fertility. The next morning, mated females were killed between 09:00 and 10:00 $\mathrm{h}$ to be examined for mating-induced ('reflex') ovulation.

Testicular growth and activity. Testicular weight was recorded at the time of birth, at the end of the treatment period and at various later ages until adulthood. Failure to find, beyond a certain age, a further increase in testicular weights, in control rats as well as rats treated with mifepristone, was judged the index that final adult testicular weight had been reached.

Testicular histology was examined at 17 days ( 2 days after the last injection of oil or $1 \mathrm{mg}$ mifepristone), 25 days or 57 days of age. The last group served to study 'adult testes'. Testes were fixed in Bouin's solution and embedded in paraffin wax. Sections $(0.01 \mathrm{~mm})$ were stained with haematoxylin and eosin. Histological examination comprised analysis of tubular diameters, and establishment of the most advanced stage of spermatogenesis in growing testes (according to Russell et al., 1987). Tubular diameters were estimated from the measurement of the diameter of 40 circular tubular sections per rat ( 4 animals per group) with the aid of a calibrated ocular micrometer.

Testicular function was assessed in various ways. Firstly, the serum concentrations of testosterone were measured in adult animals (age 80-120 days). Testosterone in blood was measured by radioimmunoassay as described by Verjans et al. (1973). Interassay variation of the assay is $15 \%$ and the sensitivity $25 \mathrm{pg}$. Secondly, accessory sex organ weights were recorded at autopsy in groups of intact rats and rats that had been castrated and treated, subsequently, for 3 weeks with $0.1 \mathrm{mg}$ testosterone propionate per day.

Rats were examined for fertility. As a first crude approach, 60-day-old males were caged with normal females for 5 days. These females were then examined 2-3 weeks later for pregnancies and litter sizes were recorded. As a second 
approach, mifepristone-treated males were caged individually with 2-3 females and daily vaginal smears were taken to record vaginal plugs as evidence of successful copulation. Mated females were examined for pregnancies or further matings when pregnancy did not follow mating. Once pregnancy could be unequivocally established by palpation of implantation sites in the uterine horns, females were caged singly to allow for parturition and the recording of litter size.

Dose dependence of the effects of mifepristone on male and female reproductive function. Newborn male and female rats were treated, on alternate days, from the day of birth until Day 15 with mifepristone $(1 \cdot 0,0.2$ or $0.04 \mathrm{mg})$ or oil only. The effect on females was evaluated by examining ovaries on Day 100. The effect on males was evaluated through the study of testis size on Days 37, 57 and 80.

Male sexual behaviour in adulthood. Adult male rats were placed together with oestrous female rats for the study of sexual behaviour during the first half of the dark period of the day. Ovariectomized females were pretreated with $0.02 \mathrm{mg}$ oestradiol benzoate at $48 \mathrm{~h}$ and $2.5 \mathrm{mg}$ progesterone at $4 \mathrm{~h}$ before the test. Sexual activity was recorded for a 15-min period. The behaviours and time periods recorded were: mounts without and with intromission, ejaculation; latency from start of the test to first contact (contact latency); time between first contact and ejaculation (ejaculation latency); time between ejaculation and the next mount (refractory period).

Tests were carried out at 1-week intervals with intact males. Then 6 randomly selected males from both groups were castrated and injected with $0.1 \mathrm{mg}$ testosterone propionate per day and 3 more tests were performed. After the last test, and after persistent incompleteness of copulatory behaviour in mifepristone-treated males had emerged, additional injections with $0.01 \mathrm{mg}$ oestradiol benzoate were given. It is well known that aromatization of testosterone within the central nervous system is a physiologically important step for testosterone to initiate male sexual behaviour (Baum \& Vreeburg, 1973). The insufficient effect of testosterone in the behaviour tests could indicate that either an insufficient amount of oestrogen was formed or that sensitivity to oestrogen was reduced.

'Androgenic activity' and secretion of gonadotrophins. Male and female rats were treated every other day, from their day of birth onwards, with $0.05 \mathrm{ml}$ oil or $1 \mathrm{mg}$ mifepristone in the same amount of oil. On Day $15,48 \mathrm{~h}$ after the last injection on Day 13, rats were lightly anaesthetized with ether and blood was obtained by puncturing the ophthalmic venous plexus. The concentrations of FSH were determined in serum according to a previously described and validated radioimmunoassay technique (Welschen et al., 1975) using NIADDK-FSH-RP-1 as standard. The interassay variation is $9 \%$ and the sensitivity 7 ng FSH RP-1. Day 15 was chosen because control female animals were expected to show large concentrations of this hormone at that time (e.g. van den Dungen et al., 1989a).

\section{Statistics}

Results were analysed using the non-parametric median test (Siegel, 1956), Student's $t$ test, or parametric analysis of variance with the further analysis of significant differences using the Tukey's honestly significant difference (HSD) test (Kirk, 1968). Differences were judged significant when $P$ (double tailed) was 0.05 or less.

\section{Results}

\section{Adrenal gland weight development}

Treatment with mifepristone caused a reduction of the weight of the adrenal glands in male and female animals at the end of the treatment period (Table 1). Several weeks after the cessation of treatment adrenal gland weight was still below normal, but the difference had disappeared in adult animals. The usual sex difference during adulthood in the size of the adrenal glands was found.

Table 1. Adrenal gland development after treatment of rats with mifepristone in infancy ( $5-8$ rats per group)

\begin{tabular}{lccc}
\hline $\begin{array}{l}\text { Age } \\
\text { (days) }\end{array}$ & Controls & Mifepristone & $\begin{array}{c}\text { Significance } \\
\text { (Student's } t \text { ) }\end{array}$ \\
\hline $18^{*}$ & $4 \cdot 8 \pm 0 \cdot 2$ & $2 \cdot 8 \pm 0 \cdot 1$ & $P<0 \cdot 01$ \\
$20^{*}$ & $5 \cdot 9 \pm 0 \cdot 2$ & $3 \cdot 9 \pm 0 \cdot 1$ & $P<0 \cdot 01$ \\
$57^{*}$ & $26 \pm 1$ & $21 \pm 1$ & $P<0 \cdot 05$ \\
120 (males) & $23 \pm 1$ & $24 \pm 2$ & n.s. \\
120 (females) & $35 \pm 2$ & $34 \pm 2$ & n.s. \\
\hline
\end{tabular}

*Sexes combined. 


\section{Bodyweight development and onset of puberty in males and females}

As shown in Table 2, after the onset of treatment on Day 1 and on Day 4 there was a statistically significant delay of puberty in male rats as judged from age and bodyweight on the day of balano-preputial skinfold cleavage. Starting treatment on Day 4 seemed more effective in this respect than starting on Day 1. After balano-preputial skinfold cleavage no abnormalities remained in the aspect of the penis: specifically, loosening of the frenulum occurred in all animals.

Table 2. Effect of treatment during infancy with mifepristone on the age at 'puberty' (median and range) as identified by (a) balano-preputial skinfold cleavage in males and (b) the day of vaginal opening in females (12-20 rats per group)

\begin{tabular}{|c|c|c|c|c|c|}
\hline \multirow{2}{*}{$\begin{array}{l}\text { Treatment } \\
\text { period }\end{array}$} & \multicolumn{2}{|c|}{ Control } & \multicolumn{2}{|c|}{ Mifepristone } & \multirow[b]{2}{*}{ Significance } \\
\hline & Age (days) & Body wt (g) & Age (days) & Body wt (g) & \\
\hline (a) Day 1-15 & $\begin{array}{c}47 \\
(42-50)\end{array}$ & $\begin{array}{c}170 \\
(152-203)\end{array}$ & $\begin{array}{c}50 \\
(47-58)\end{array}$ & $\begin{array}{c}185 \\
(161-212)\end{array}$ & $P<0.01^{*}$ \\
\hline Day 4-18 & $\begin{array}{c}48 \\
(46-52)\end{array}$ & $\begin{array}{c}161 \\
(155-184)\end{array}$ & $\begin{array}{c}60 \\
(54->65)\end{array}$ & $\begin{array}{c}213 \\
(188->220)\end{array}$ & $P<0.001^{*}$ \\
\hline (b) Day $1-15$ & $\begin{array}{c}34 \\
(31-36)\end{array}$ & & $\begin{array}{c}32 \\
(31-34)\end{array}$ & & $P<0.01+$ \\
\hline Day 4-18 & $\begin{array}{c}33 \\
(32-35)\end{array}$ & & $\begin{array}{c}31 \\
(30-32)\end{array}$ & & n.s. t $^{-}$ \\
\hline
\end{tabular}

*Median test of ages and bodyweights of corresponding groups (Siegel, 1956).

$\uparrow$ Median test of ages of corresponding groups (Siegel, 1956).

Vaginal opening occurred earlier by 1 or 2 days in mifepristone-treated rats. Vaginal opening was followed by vaginal smear cornification within 1-2 days in all rats. Treatment from Day 4 was not more effective in this respect. Vaginal smears in all groups of rats showed cyclicity for the first 3 weeks after vaginal opening with two exceptional animals in the group treated from Day 1 (Table 3 ). These two rats showed uninterrupted vaginal cornification and anovulatory polyfollicular ovaries on Day 50.

Table 3. Ovarian activity and function in female rats treated with mifepristone or oil ( $=$ control) in infancy, evaluated by vaginal smear cycles recorded in all animals during the 4 weeks after vaginal opening

\begin{tabular}{|c|c|c|c|}
\hline & $\begin{array}{l}\text { Mifepristone on } \\
\text { Days 4-16 }\end{array}$ & $\begin{array}{l}\text { Mifepristone on } \\
\text { Days 1-15 }\end{array}$ & $\begin{array}{l}\text { Control } \\
\text { females }\end{array}$ \\
\hline No of rats & 9 & 17 & 23 \\
\hline $\begin{array}{l}\text { Acyclic } \\
\text { ('persistent oestrous') }\end{array}$ & 0 & 2 & 0 \\
\hline 4-day cycles & 4 & 19 & 16 \\
\hline 5-day cycles & 16 & 20 & 36 \\
\hline 6-day cycles & 9 & 4 & 14 \\
\hline$>$ 6-day cycles & 4 & 3 & 12 \\
\hline 'Pseudopregnancies' & 2 & 5 & 2 \\
\hline $\begin{array}{l}\text { Pregnant after }+ \text { males } \\
\text { from } 70 \text { days of age }\end{array}$ & n.d. & $9 / 15$ & $10 / 11^{*}$ \\
\hline Litter size & n.d. & $5 \cdot 5 \pm 1 \cdot 1$ & $9.7 \pm 0.6+$ \\
\hline $\begin{array}{l}\text { Corpora lutea of } \\
\text { pregnancy }\end{array}$ & n.d. & $12 \cdot 3 \pm 0 \cdot 2$ & $11 \cdot 2 \pm 1 \cdot 4 t$ \\
\hline
\end{tabular}

${ }^{*} P>0.05$, Fisher exact probability test.

$\dagger P<0.01$, Student's $t$ test.

$\ddagger P>0 \cdot 1$. 
Treatment with mifepristone did not affect body weight development in female rats (data not shown). Mifepristone-treated male rats showed reduced growth around 'puberty' resulting in slightly but statistically significantly lower bodyweights between Days 50 and 100. In adulthood, however, their bodyweights were again similar to that of the control animals (data not shown).

\section{Reproductive function in females}

At the age of 2 months rats treated with mifepristone became pregnant from their caging with fertile males as did control female animals (Table 3). After pregnancy of normal duration the litter size of the first group of rats appeared significantly lower than that of controls. The numbers of corpora lutea of pregnancy were not different between the two groups.

Autopsy of mifepristone-treated females revealed abnormalities in the macroscopic appearance of the oviducts and ovarian capsules. The oviducts in control rats showed the normal 6-8 loops between the fimbriae and the entrance into the uterine horn. Mifepristone-treated rats showed only 3-4 loops: these tubal loops were larger and more elongated than in control rats. Control rats showed the usual minor opening, which is difficult to identify, between the abdominal cavity and the space below the ovarian capsule. Mifepristone-treated rats, in contrast, showed an easily recognizable and large opening between abdominal and subcapsular space.

At the age of 100 days, 10 of the 12 females which had been treated with $1 \mathrm{mg}$ mifepristone from Day I, showed uninterrupted vaginal cornification. Upon caging with sexually active males they showed oestrous behaviour and allowed intromissions and ejaculations to take place. On the following morning all rats showed polyfollicular ovaries with no corpora lutea and no evidence of ovulation induced by mating during the preceding night. Two of the animals showed signs of tubal and ovarian infections: hydrosalpinx and adhesions between the ovary and the surrounding ovarian capsule.

\section{Testicular growth and activity}

The effect of treatment with mifepristone on testis growth was similar in rats treated from Day 4 and from Day 1. Figure 1 shows the combined results of the two groups. Treatment with mifepristone reduced testicular growth during the treatment period. Thereafter, the reduction appeared permanent as testes did not grow beyond around $1000 \mathrm{mg}$.

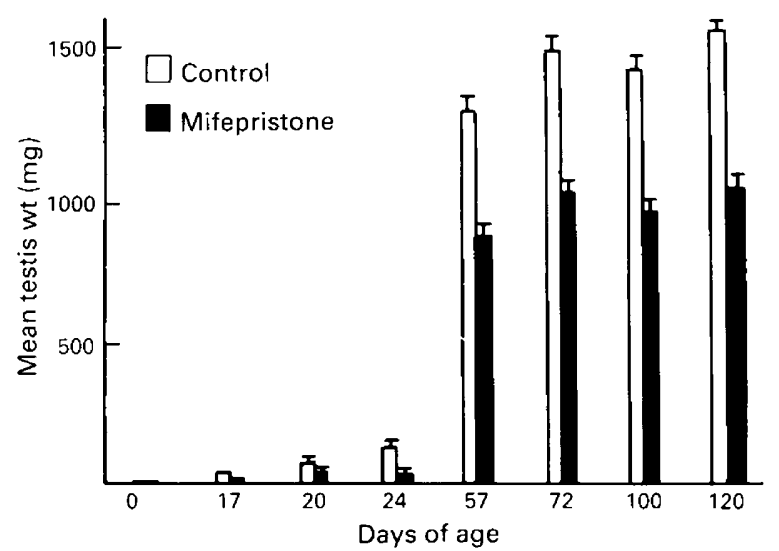

Fig. 1. Testicular growth in rats after treatment with mifepristone in infancy. Values are means \pm s.e.m. of 4-6 rats per group.

Seminal tubular diameters increased as the age of the animals increased. Mifepristone-treated rats had tubular diameters similar to those of control rats immediately after cessation of the treatment on Day 17 ( $68 \pm 3 \mu \mathrm{m}$ and $73 \pm 3 \mu \mathrm{m}$ respectively) and as adults ( $241 \pm 4$ and $247 \pm 4 \mu \mathrm{m}$ 
respectively). At 25 days of age, however, they showed smaller tubular diameters than did control animals $(91 \pm 2 \mu \mathrm{m}$ and $118 \pm 2-\mu \mathrm{m}$ respectively; $P<0.01$, ANOVA and HSD-test). Adult testicular histology after mifepristone in infancy seemed 'healthy' in all respects and not different from controls. The most advanced stages of spermatogenesis present on Days 17 and 25 were qualitatively not different between the two groups. Quantitatively, however, numbers of cells beyond leptotene/zygotene spermatids in controls outnumbered those in mifepristone-treated animals on Day 25.

Adult rats treated with mifepristone in infancy showed normal blood concentrations of testosterone (Table 4). In agreement with this finding, the accessory sex organs in mifepristone-treated rats were similar to those in controls: the condition was found both while the rats were intact and after the rats had been castrated and injected with testosterone propionate.

Table 4. Testicular activity and function in 100-120-day-old rats treated with oil $(=$ control) or mifepristone in infancy

\begin{tabular}{lccc}
\hline & Control & Mifepristone & $\begin{array}{c}\text { Significance } \\
(t \text { test })\end{array}$ \\
\hline Intact rats & & & \\
Testis (mg) & $1453 \pm 25(12)$ & $976 \pm 50(13)$ & $P<0.001$ \\
Epididymis (mg) & $433 \pm 10(8)$ & $322 \pm 12(9)$ & $P<0.001$ \\
Seminal vesicles (mg) & $272 \pm 30(6)$ & $219 \pm 20(7)$ & n.s. \\
Testosterone (ng/ml serum) & $5.0 \pm 0 \cdot 7(12)$ & $3.5 \pm 0.4(13)$ & n.s. \\
\hline
\end{tabular}

Castrated rats chronically treated with $0.1 \mathrm{mg}$ testosterone propionate/day Seminal vesicles $(\mathrm{mg}) \quad 317 \pm 40(5) \quad 305 \pm 35(5) \quad$ n.s.

Values are mean \pm s.e. for the no. of rats indicated in parentheses.

Adult control rats proved to be fertile upon their caging with normal female rats (5 out of 5 rats examined). None of the females caged with mifepristone-treated males became pregnant. Subsequently, 6 animals of the latter group were caged with 2-3 females each. Vaginal smears revealed the occurrence of mating. After 5 weeks all 6 males had impregnated at least 1 female. However, 'infertile' matings (i.e. females only becoming pseudopregnant) or vaginal cycles without mating were recorded as well. Litter size developing from matings with mifepristone-treated males was of the normal order $8 \cdot 8 \pm 1 \cdot 2$ young in 12 litters.

\section{Dose dependence of the effects of mifepristone}

As shown in Fig. 2, reducing the amount of mifepristone in infancy to $20 \%$ did not ameliorate impairment of testicular growth. In fact, a further decrease to $4 \%$ still affected testis size significantly by Day 80 .

Of 12 female rats, treated with $1 \mathrm{mg}$ mifepristone every 2 days between Days 1 and 15,10 showed persistent vaginal cornification and anovulatory ovaries at the age of 100 days (see above). Of the 5 female rats treated with $0.2 \mathrm{mg}$ mifepristone, 3 showed an anovulatory ovarian condition on Day 100 . None of 5 rats treated with $0.04 \mathrm{mg}$ mifepristone or 10 rats receiving oil only showed this condition.

\section{Male sexual behaviour in adulthood}

Copulatory behaviour in male rats treated with mifepristone was similarly deficient whether treatment had started on Day 1 or Day 4 . Only the results obtained with the animals treated from Day 1 are presented in Fig. 3 and Table 5.

After 2 preliminary tests without behavioural recording, all adult male rats treated with mifepristone in infancy showed sexual behaviour when caged with oestrous female rats. Sexual behaviour was different from that of control male animals in that the frequency of mounts and 


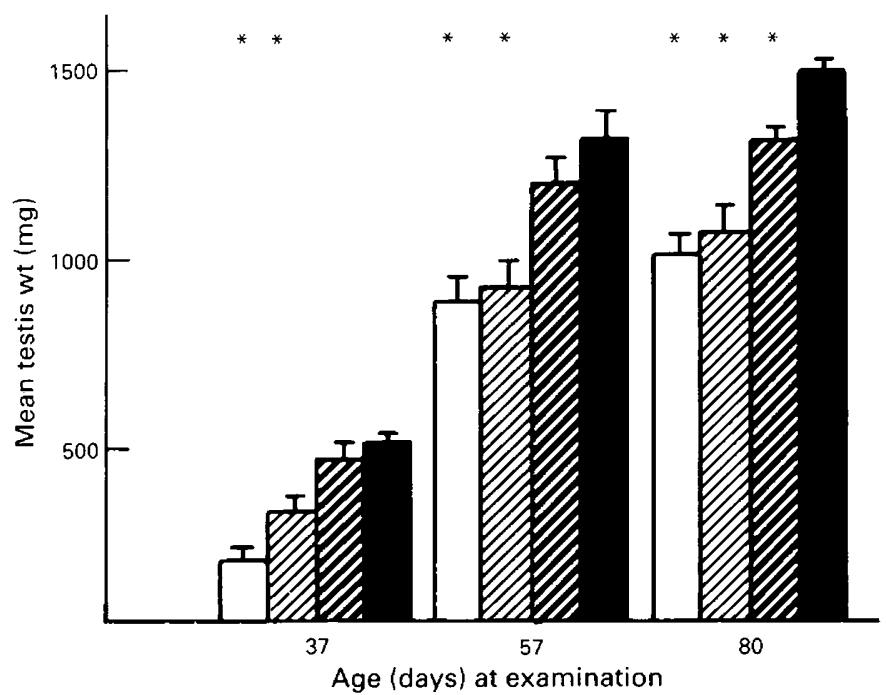

Fig. 2. Testicular growth in male rats treated every 2 days with $1 \mathrm{mg}$ (open bars), $0 \cdot 2 \mathrm{mg}$ (lightly hatched bars), $0.04 \mathrm{mg}$ (heavily hatched bars) or $0 \mathrm{mg}$ mifepristone (closed bars) between Days 1 and 15 of life. Asterisks indicate significant differences from the respective groups of control rats. Values are means \pm s.e.m. of $4-6$ rats per group.

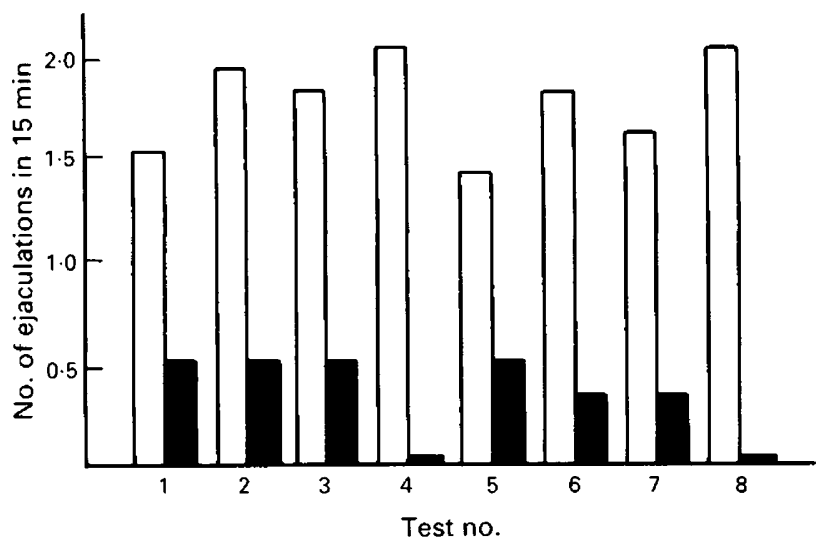

Fig. 3. Mean number of ejaculations recorded per 15-min test for adult male rats treated with oil (control; $\mathrm{N}=10$ ) or mifepristone in infancy ( $1 \mathrm{mg}$ every other day from Day 1 to Day 15; $\mathrm{N}=10$ ). After Test 3, 6 males from both groups were castrated and treated with $0 \cdot 1 \mathrm{mg}$ testosterone propionate per day (Tests 4-6). These males were then treated with testosterone propionate $+0.01 \mathrm{mg}$ oestradiol benzoate (Tests 7-8).

intromissions (i.e. the numbers of those behaviours per minute of the test) was lower in the mifepristone-treated group. Accordingly, ejaculations occurred only rarely in this group. This difference emerged even in the first test and remained stable thereafter (Fig. 3). After castration, and during treatment with testosterone propionate, the difference in sexual behaviour display between control and mifepristone-treated rats remained unchanged (Fig. 3; Table 5).

The sexual behaviour display of control and mifepristone-treated male rats did not alter when supplementary injections with oestradiol benzoate were given. However, these injections did have another marked effect. Mifepristone-treated rats, when caged together with control animals, 
Table 5. Characteristics of copulatory behaviour of adult male rats treated with oil or mifepristone in infancy

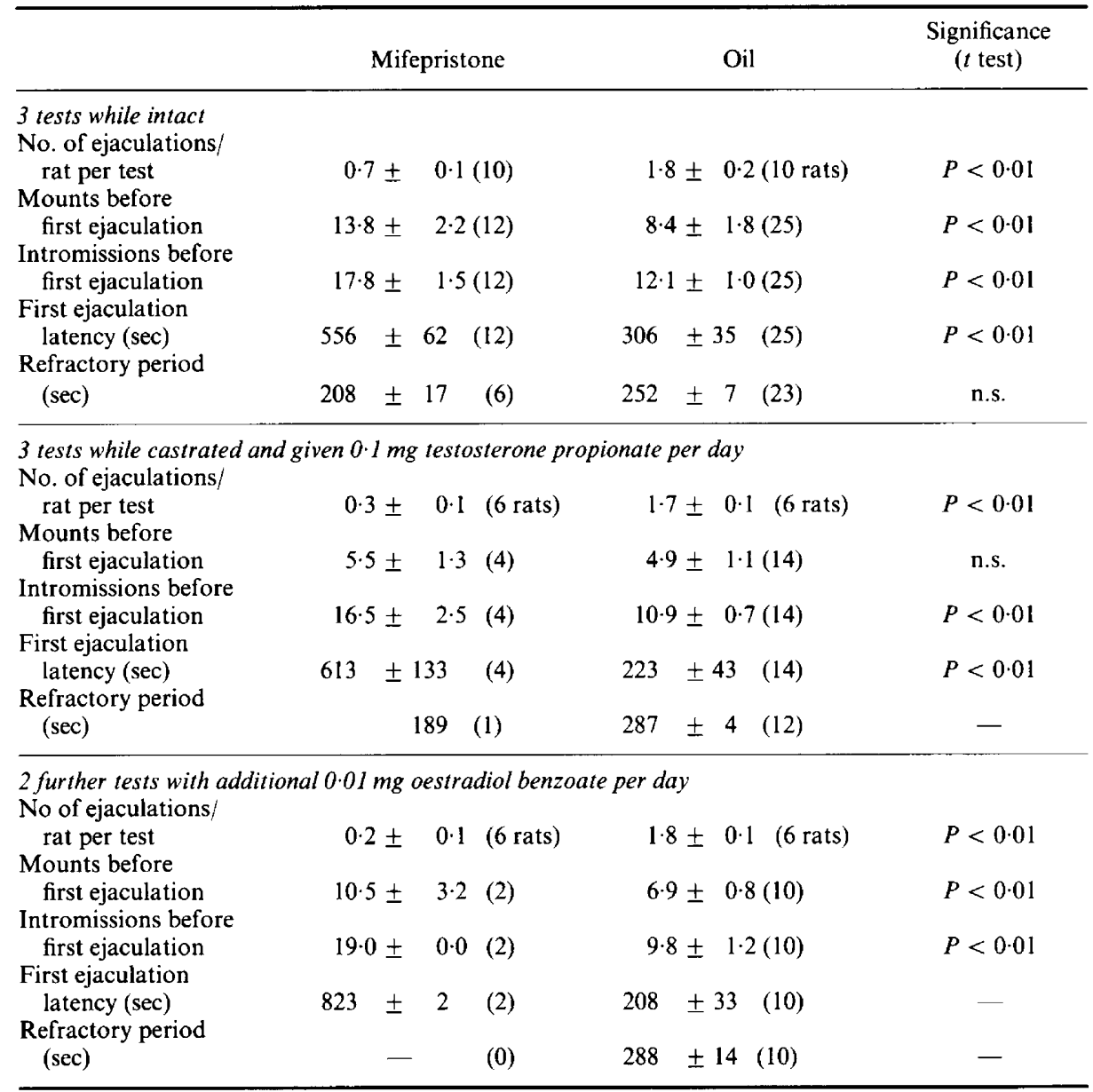

Values are mean \pm s.e.m. for the no. of rats indicated in parentheses.

quickly started to show several characteristics of female sexual behaviour including proceptive behaviours, i.e. hop/dart and ear wiggling. Upon being mounted, all 6 rats showed lordosis resulting in lordosis quotients of $80-100$. The control male rats only rarely showed lordotic response when being mounted by the mifepristone-treated cagemate (lordosis quotient $<0.10 ; P<0.01$, Student's $t$ ). The control males were never observed to display soliciting behaviours like hop/dart and ear wiggling.

\section{'Androgenic activity' and secretion of gonadotrophins}

Injections of mifepristone in infant male rats had no intrinsic 'androgenic' effect as judged by the unstimulated weight of the seminal vesicles at the end of the treatment period on Day 15 (Table 6).

The results obtained with the measurement of FSH on Day 15 are also presented in Table 6 . Blood concentrations of FSH in males were not significantly affected by the treatment with mifepristone. However, in females, the blood FSH concentrations in rats treated with mifepristone 
Table 6. Blood concentrations on FSH on Day 15 in male and female rats, and testis and seminal vesicle weight in male rats after treatment with mifepristone (1 mg every other day from the day of birth)

\begin{tabular}{lrrcc}
\hline & Mifepristone & \multicolumn{1}{c}{ Control } & $\begin{array}{c}\text { Significance } \\
(t \text { test })\end{array}$ \\
\hline Males & $17 \pm 3(7)$ & $41 \pm 4(8)$ & $P<0.01$ \\
$\quad$ Testis wt (mg) & $4 \pm 1(7)$ & $6 \pm 1(8)$ & $P<0.05$ \\
Seminal vesicles wt (mg) & $320 \pm 45(7)$ & $376 \pm 40(8)$ & n.s. \\
FSH conc. (ng/ml) & $534 \pm 90(13)$ & $1840 \pm 210(6)$ & $P<0.001$ \\
Females & & &
\end{tabular}

were significantly below those of controls. The latter animals showed the expected high levels of FSH characteristic for this age period.

\section{Discussion}

The present experiments investigated persistent reproductive developmental effects in male and female rats of treatment with mifepristone in infancy.

Female rats showed abnormalities in several respects: interference, after some delay, with normal ovarian cyclicity; reduced fertility; abnormalities in ovarian capsular and oviducal morphology. Interference with ovarian cyclicity ('persistent oestrous syndrome') after a period with seemingly normal ovulatory cycles resembles the effect observed of the treatment of female rats on Day 5 with a low dose of testosterone propionate (Swanson \& Van der Werff ten Bosch, 1964). This so-called 'delayed early androgen syndrome' has been explained as partial masculinization, in infancy, of the developing structures and systems involved in the release of an ovulatory quota of $\mathrm{LH}$ in response to oestrogen during adulthood. More recent evidence has indicated that this masculinization is in effect brought about by intrahypothalamic formation of oestrogenic metabolites from aromatizable precursors such as testosterone. The similarity of the effect of a single low dose of testosterone propionate on Day 5 and the regular administration of a large quantity of mifepristone from Day 1 to Day 15 could be explained as an indication that the latter compound has some, albeit very weak, intrinsic androgenic or oestrogenic effect. There is no direct evidence to support weak androgenic or oestrogenic actions of mifepristone in adult or neonatal rats (Philibert et al., 1985; van der Schoot et al., 1990; Table 6 of this study). Moreover, reducing the amount of mifepristone by $80 \%$ resulted in a similar 'delayed early androgen syndrome', as if the effective amount of the injected compound had remained unchanged.

An alternative explanation for the effect of neonatal administration of mifepristone in females emerges from the supposed protective action of neonatal progesterone against effects of the high circulating concentrations of oestrogen in females during infancy (Shapiro et al., 1976). Through the antagonistic effect of mifepristone to progesterone action these high levels of endogenous steroids (Meijs-Roelofs et al., 1973) could act to masculinize the developing females to some extent. It is then easier to understand why the effect on cessation of ovarian cycles around Day 100 occurred with the highest dose of mifepristone and $20 \%$ of that dose. Both quantities of mifepristone could suffice to neutralize the protective action of progesterone.

Ovarian cyclicity during the first months of life was not associated with unimpaired fertility: pregnancies were initiated seemingly normally but litter size at parturition was below that of controls. The reduced litter size was unlikely to be associated with low numbers of ruptured follicles at ovulation as, post partum, normal numbers of corpora lutea of pregnancy were found. It seems more likely that loss of ovulated eggs occurred between ovulation and growth of fetuses. Part of this loss could be associated with the abnormal oviducal and ovarian capsular morphology in 
mifepristone-treated rats. The abnormal formation of tubal loops and the large hole between the abdominal cavity and subcapsular space, which is difficult to visualize in normal female rats (Wimsatt \& Waldo, 1945), could interfere with the normal egg and sperm transport mechanisms. This potential 'anatomical' explanation for impaired fertility deserves further investigation.

There have been earlier reports of oviducal morphological abnormalities after perinatal exposure of rats to oestrogenic or androgenic steroid hormones which show similarity with those observed in the present study (Greene et al., 1939, 1940). The similarity supports, from another point of view, the idea discussed above of a weak oestrogenic or androgenic action of mifepristone.

Treatment with mifepristone markedly affected adrenal gland development. Suppression of adrenal growth seemed to persist for weeks after cessation of the treatment. However, beyond Day 100, males and females had developed glands of normal size. This action of treatment with mifepristone in infancy points to interference with the normal development of the hypothalamopituitary-adrenal axis. There have been several reports of an antiglucocorticoid action of mifepristone (Klijn et al., 1989). Such action should be expected, however, to result in stimulatory rather than inhibitory action on adrenal growth in accordance with results obtained with drugs interfering with the biosynthesis of glucocorticoids (Goldman, 1967). In adult rats we have been unable to discover any action of mifepristone on the hypothalamo-pituitary-adrenal axis resulting in weight change of the adrenals (van der Schoot et al., 1987, 1989).

Treatment with mifepristone in infancy permanently affected testicular development. The treatment directly reduced testis growth. This effect seemed associated with delay in testicular maturation as 'male puberty' became delayed as well. Adult testicular weight remained stable at about two thirds of that of controls. Reduced testis weight in adulthood was, however, not associated with impaired testicular testosterone secretion: neither the concentrations of testosterone in blood nor the growth of the accessory sex organs seemed affected by the treatment in infancy. The effect on testicular growth became less when the dose of mifepristone in infancy was reduced. However, even at $0.04 \mathrm{mg}$ every 2 days there was a significant reduction of adult testicular weight.

'Male puberty' as evidenced by cleavage of the balano-preputial skinfold was affected by treatment with mifepristone in infancy, while female puberty as evidenced by vaginal opening or first occurrence of a cornified vaginal smear was virtually not. This divergence of effect was similarly noticed in a recent study during which neonatal male and female rats were injected with an antagonist of gonadotrophin releasing-hormone (van der Dungen et al., 1989a). Evidently, male puberty seems more susceptible to neonatal manipulation with drugs affecting testicular growth than does female puberty to procedures affecting ovarian growth conditions.

There have been more reports indicating permanent impairment of testicular growth, copulatory behaviour, and fertility after treatment of male rats in infancy. Effective treatments are those starting early after birth and involving injections of oestradiol, testosterone or dihydrotestosterone (Wilson \& Wilson, 1943; Feigelson, 1986). The apparently permanent effect of such treatments can be best understood as resulting from the interference with the normal exposure to gonadotrophins of the developing testes. In line with this assumption a similar effect on male reproductive development has been obtained by suppression of the secretion neonatally of gonadotrophins through injection of a GnRH antagonist (van den Dungen et al., 1989a, b; Kolho \& Huhtaniemi, 1989) or antiserum against gonadotrophins (Goldman \& Mahesh, 1970) or against LHRH (Bercu et al., 1977).

The measurement of FSH on Day 15, after injections of $1 \mathrm{mg}$ mifepristone every other day from Day 1, did not reveal suppression in males. The effects found in males in the present study therefore do not seem to result from testicular growth suppression secondary to suppressed secretion of gonadotrophins. One might envisage a direct action of mifepristone on the developing testis but further work should be done to substantiate this hypothesis. In females there was a significant reduction of the extremely high blood concentrations of FSH characteristic for this age (MeijsRoelofs et al., 1973; van den Dungen et al., 1989b). There is no obvious explanation for the sex difference found in the effect of mifepristone on FSH secretion in infancy. The enhanced secretion of FSH around Day 15 in females could perhaps represent the result of specific stimulation. 
Mifepristone might act, in females, not primarily to suppress FSH secretion but rather to inhibit the action of the stimulatory process responsible for the enhanced FSH secretion around Day 15. If this were so there is no need to expect intrinsic suppressive action of mifepristone on gonadotrophin secretion. Indeed, in adult animals a stimulatory rather than inhibitory action on gonadotrophins in females has been found (Bakker et al., 1987; van der Schoot et al., 1990).

Sexual behaviour in males treated with mifepristone as infants was different from that of controls: most markedly, ejaculations occurred seldom during 15 min tests. Small testes, while the animals were studied intact, played no crucial role as testes appeared to secrete amounts of testosterone not different from those of controls. Also, treatment with testosterone after castration did not improve sexual behaviour. The further inclusion of oestradiol benzoate with the testosterone treatment was also unable to improve copulatory behaviour, suggesting that this deficiency in mifepristone-treated males was not due to insufficient availability of oestrogen through aromatization of testosterone (Baum \& Vreeburg, 1973). A similar copulatory behaviour deficiency has been described after the suppression, during infancy, of gonadotrophin secretion (Feigelson, 1986; Huhtaniemi et al., 1986; van den Dungen et al., 1989b; Kolho \& Huhtaniemi, 1989).

The observation of female-like sexual behaviour of mifepristone-treated males during treatment with testosterone propionate and oestradiol benzoate may indicate that the treatment with mifepristone during infancy interfered with the normal processes in male rats leading to 'masculinization' of the developing hypothalamic substrates of sexual behaviour. Masculinization requires testosterone or its aromatized metabolites (van der Schoot, 1980). Failure of normal masculinization through treatment with mifepristone indicates that this compound has no intrinsic testosterone- or oestrogen-like properties.

Male sexual behaviour deficiency was associated with relative infertility. When first placed with females for some days none of the males was able to induce a pregnancy. However, prolonged placement with females from around Day 100 resulted in impregnation by all males and the production of litters of normal size. Infertility seems to result from relative inabilty of the males to ejaculate but not from any inherent abnormality of ejaculated spermatozoa. Similar 'relative infertility' has been reported from studies of male rats treated with a large dose of dihydrotestosterone propionate in infancy (Feigelson, 1986; P. van der Schoot, unpublished observation) or an antagonist against LHRH (van den Dungen et al., 1989a, b).

We thank Dr R. DeRaedt (Roussel-Uclaf, Romainville, France) for supplying mifepristone; and Mr P. Woutersen and Mrs M. Ooms for measuring blood hormone concentrations.

\section{References}

Bakker, G.H., Setyono-Han, B., Henkelman, M.S., de Jong, F.H., Lamberts, S.W.J., van der Schoot, P. \& Klijn, J.G.M. (1987) Comparison of the action of the antiprogestin Mifepristone (RU486), the progestin Megestrol acetate, the LHRH analog Buserelin, and ovariectomy in treatment of rat mammary tumors. Canc. Treatm. Rep. 71, 1021-1027.

Bakker, G.H., Setyono-Han, B., Portengen, H., de Jong, F.H., Foekens J.A. \& Klijn, J.G.M. (1989) Endocrine and antitumor effects of combined treatment with an antiprogestin and antiestrogen or luteinizing hormone-releasing hormone agonist in female rats bearing mammary tumors. Endocrinology 125, 1593-1598.

Baum, M.J. \& Vreeburg, J.T.M. (1973) Copulation in castrated male rats following combined treatment with estradiol and dihydrotestosterone. Science, $N Y$ 182, 283-285.

Beach, F.A., Noble, R.G. \& Orndoff, R.K. (1969) Effects of perinatal androgen treatment on responses of male rats to gonadal hormones in adulthood. J. comp. Physiol. Psychol. 68, 490-497.

Bercu, B.B., Jackson, I.M.D., Sawin, C.T., Safaii, H. \& Reichlin, S. (1977) Permanent impairment of testicular deveiopment after transient immunological blockade of endogenous luteinizing hormone releasing hormone in the neonatal rat. Endocrinology 101, 1871-1879.

de Jong, R.A.P. \& van der Schoot, P. (1979) Advancement of sexual maturation in male rats by pituitary transplants. Biol. Reprod. 21, 1263-1271.

Feigelson, M. (1986) Suppression of testicular maturation and fertility following androgen administration to neonatal male rats. Biol. Reprod. 35, 1321-1332.

Gerall, A.A., Hendricks, S.E., Johnson, L.L. \& Bounds, T.W. (1967) Effects of early castration in male rats on adult sexual behavior. J. comp. Physiol. Psychol. 64, $206-212$. 
Goldman, A.S. (1967) Experimental model of congenital adrenal cortical hyperplasia produced in utero with an inhibitor of $11 \beta$-steroid hydroxylase. J. clin. Endocr. Metab. 27, 1390-1394.

Goldman, B.D. \& Mahesh, V.B. (1970) Induction of infertility in male rats by treatment with gonadotropin antiserum during neonatal life. Biol. Reprod. 2, 444-451.

Grady, K.L., Phoenix, C.H. \& Young, W.C. (1965) Role of the developing rat testis in differentiation of the neural tissues mediating mating behavior. J. comp. Physiol. Psychol. 59, 176-182.

Greene, R.R., Burrill, M.W. \& Ivy, A.C. (1939) Experimental intersexuality: the paradoxical effects of estrogens on the sexual development of the female rat. Anat. Rec. 74, 429-438.

Greene, R.R., Burrill, M.W. \& Ivy, A.C. (1940) Experimental intersexuality: the effects of estrogens on the antenatal sexual development of the rat. Am. J. Anat. 67, 305-345.

Huhtaniemi, I.T., Nevo, N., Amsterdam, A. \& Naor, Z. (1986) Effect of postnatal treatment with a gonadotropin-releasing hormone antagonist on sexual maturation of male rats. Biol. Reprod. 35, 501-507.

Kirk, R.E. (1968) Experimental Design: Procedures for the Behavioral Sciences. Brooks/Cole, Belmont.

Klijn, J.G.M., de Jong, F.H., Bakker, G.H., Lamberts, S.W.J., Rodenburg, C.J. \& Alexieva-Figush, J. (1989) Antiprogestins, a new form of endocrine therapy for human breast cancer. Canc. Res. 49, 2851-2856.

Kolho, K.-L. \& Huhtaniemi, I. (1989) Neonatal treatment of male rats with a gonadotropin-releasing hormone antagonist impairs ejaculation and fertility. Physiol. Behav. 46, 373--377.

Meijs-Roelofs, H.M.A., Uilenbroek, J.Th.J., de Jong, F.H. \& Welschen, R. (1973) Plasma oestradiol-17 $\beta$ and its relationship to serum follicle-stimulating hormone in immature female rats. J. Endocr. 59, 295-304.

Philibert D., Moguilewsky M., Mary I., Lecaque D., Tournemine C., Sechi J. \& Deraedt R. (1985) Pharmacological profile of RU486 in animals. In The Antiprogest in Steroid RU486 and Human Fertility Control, pp. 49-68. Eds E. E. Baulieu \& S. Segal. Plenum Press, New York.

Russell, L.D., Alger, L.E. \& Nequin, L.G. ( 1987) Hormonal control of pubertal spermatogenesis. Endocrinology 120, 1615-1632.

Shapiro, B.H., Goldman, A.S., Bongiovanni, A.M. \& Marino, J.M. (1976) Neonatal progesterone and feminine sexual development. Nature, Lond. 264, $795-796$.
Siegel, S. (1956) Nonparametric Statistics for the Behavioral Sciences. McGraw-Hill, Kogakusha.

Swanson, H.E. \& van der Werff ten Bosch, J.J. (1964) The early androgen syndrome: differences in response to prenatal and postnatal administration of various doses of testosterone propionate in female and male rats. Acta endocr., Copenh. 47, 37-50.

van den Dungen, H.M., van Dieten, J.A.M.J., Tilders, F.J.H., van Rees, G.P. \& Schoemaker, J. (1989a) Administration of a GnRH-antagonist to immature rats affects subsequent female and male pubertal development differently. Acta endocr., Copenh. 120, $778-784$.

van den Dungen, H.M., Dijkstra, H., Hiehle, M.A.H., van Rees, G.P. \& Schoemaker, J. (1989b) Effect of LHRH antagonist administration to immature male rats on sexual development. Physiol. Behav. 46, $779-785$.

van der Schoot, P. (1980) Effects of dihydrotestosterone and oestradiol on sexual differentiation in male rats. $J$. Endocr. 84, 397-407.

van der Schoot, P., Bakker, G.H. \& Klijn, J. (1987) Effects of the progesterone antagonist RU486 (Mifepristone) on ovarian activity in rats. Endocrinology 121, 1375-1382.

van der Schoot, P., Uilenbroek, J.Th.J. \& Slappendel, E.J. (1989) Failure of two progesterone-antagonists to affect luteal activity in lactating rats. J. Reprod. Fert. 87, 593-601.

van der Schoot, P., Uilenbroek, J.Th.J. \& Slappendel, E.J. (1990) Effect of the progesterone-antagonist Mifepristone on the hypothalamo-hypophysealovarian axis in rats. $J$. Endocr. 124, 725-732.

Verjans, H.L., Cooke, B.A., de Jong, C.C.M. \& van der Molen, H.J. (1973) Evaluation of a radioimmunoassay for testosterone estimation. J. Steroid Biochem. 4, 665-673.

Welschen, R., Osman, P., Dullaart, J., de Greef, W.J., Uilenbroek, J.Th.J., \& de Jong, F.H. (1975) Levels of follicle-stimulating hormone, luteinizing hormone, oestradiol-17 $\beta$ and progesterone, and follicular growth in the pseudopregnant rat. $J$. Endocr. 64, $37-47$.

Wilson, J.G. \& Wilson, H.C. (1943) Reproductive capacity in adult male rats treated prepuberally with androgenic hormone. Endocrinology 33, 353-360.

Wimsatt, W.A. \& Waldo, C.M. (1945) The normal occurrence of a peritoneal opening in the bursa ovarii of the mouse. Anat. Rec. 93, 47-53.

Received 9 January 1990 